\title{
Conexión anómala total de venas pulmonares
}

\author{
Total anomalous connection of pulmonary veins
}

\author{
Jorge Ignacio Magaña Reyes, ${ }^{*}$ Armando Zepeda Arámbula, ${ }^{\ddagger}$ Rómulo Armenta Flores§
}

Citar como: Magaña RJI, Zepeda AA, Armenta FR. Conexión anómala total de venas pulmonares. Acta Med. 2020; 18 (4): 433-434. https://dx.doi.org/10.35366/97277

Recién nacido masculino de 15 días de vida, el cual en apariencia presentaba un corazón estructuralmente sano en estudios prenatales, al nacimiento se identificó por ecocardiografía un seno coronario dilatado, asociado a prominente vaso retrocardiaco. En un principio se pensó en una vena cava izquierda persistente con drenaje anómalo en seno coronario o en una fístula arteriovenosa pulmonar. La angiotomografía de tórax (Figura 1) demostró: retornos venosos pulmonares anómalos en forma total, con venas pulmonares derechas e izquierdas que se conectan a un colector que deriva en la vena vertical, y ascienden hasta drenar en la vena cava superior, asimismo se observó una aparente vena supernumeraria adyacente a las venas pulmonares derechas, que drena en el seno coronario; coexistió dilatación de cavidades derechas.

La conexión anómala total de venas pulmonares (CATVP) constituye de 1.5 a 5.0\% de todas las cardiopatías congénitas, con incidencia de 6.8/100,000 nacidos vivos, $70 \%$ de los casos son diagnosticados en la etapa neonatal. ${ }^{1}$ La CATVP es una cardiopatía congénita en la que no existe continuidad entre el seno venoso pulmonar (SVP) y la aurícula izquierda, ocasionando que la sangre que Ilega al SVP drene a la aurícula derecha, ya sea directamente o a través de sistemas venosos tributarios. La sangre venosa pulmonar y sistémica se mezcla en el sitio de conexión anómala, existiendo un cortocircuito entre ambas aurículas mediante comunicación interatrial de tipo orificio oval. La sobrecarga de volumen sanguíneo en las cavidades derechas y en la arteria pulmonar producen su dilatación, provocando incremento del flujo sanguíneo pulmonar y posteriormente hipertensión pulmonar, lo que a su vez llega a ocasionar hipertrofia del ventrículo derecho. ${ }^{2}$ Los tres aspectos centrales de interés clínico y quirúrgico son: a) el sitio de conexión

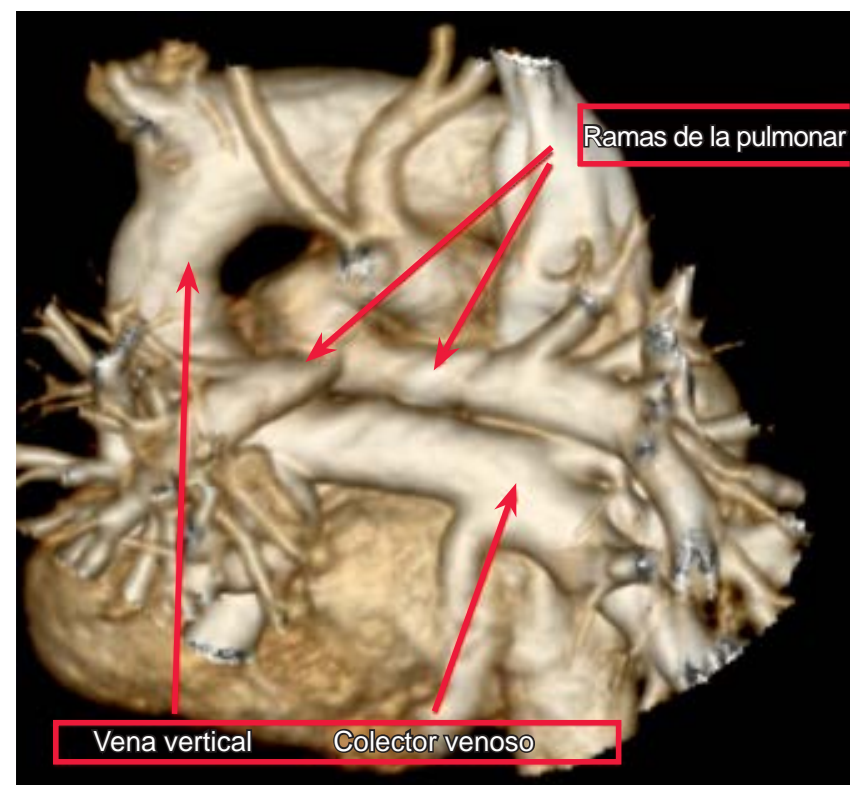

Figura 1: Reconstrucción tridimensional de angiotomografía de tórax vista del aspecto posterior del corazón, donde se observa que las venas pulmonares llegan a un colector, el cual deriva en la vena vertical, y drenan en la vena cava superior.
* Radiólogo. Especialista en Resonancia Magnética Cardiaca. Hospital Villas del Campestre.

₹ Cardiólogo Pediatra. División de Pediatría del Hospital Ángeles León.

$\S$ Cirujano Cardiotorácico. División de Cirugía del Hospital Médica Campestre.

León, Guanajuato, México.
Correspondencia:

Dr. Jorge Ignacio Magaña Reyes

Correo electrónico: magadoc@gmail.com

Aceptado: 13-01-2020.

www.medigraphic.com/actamedica

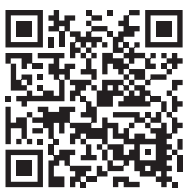


anómala de las venas pulmonares; b) la obstrucción del colector $y ; c)$ las dimensiones de la comunicación interauricular. El sitio y tipo de conexión anómala determina las características de la cirugía, requiriéndose la integración quirúrgica del SVP con la aurícula izquierda, además de la ligadura del colector que depende del sitio anatómico donde desemboque.

\section{REFERENCIAS}

1. Muñoz CL, Sánchez VC, Kuri NM. Estudio morfo patológico de la conexión anómala total de venas pulmonares. Arch Cardiol Mex. 2007; 77: 265-274.

2. Zuluaga SA, Aldana SN, Muñoz GP, Bustamante ZS, Zuluaga MN, Grand VV. Anomalías congénitas y variantes anatómicas del seno coronario. Rev Colomb Radiol. 2017; 28: 4643-4648. 